\title{
Battery Energy Storage System for PV Output Power Leveling
}

\author{
Rajkiran Singh, Seyedfoad Taghizadeh, Nadia Mei Lin Tan, and Jagadeesh Pasupuleti \\ Department of Electrical Power Engineering, Universiti Tenaga Nasional, Jalan IKRAM-UNITEN, 43000 Kajang, Selangor, Malaysia
}

Correspondence should be addressed to Nadia Mei Lin Tan; nadia@uniten.edu.my

Received 31 July 2014; Revised 1 November 2014; Accepted 4 November 2014; Published 16 December 2014

Academic Editor: Don Mahinda Vilathgamuwa

Copyright (C) 2014 Rajkiran Singh et al. This is an open access article distributed under the Creative Commons Attribution License, which permits unrestricted use, distribution, and reproduction in any medium, provided the original work is properly cited.

\begin{abstract}
Fluctuating photovoltaic (PV) output power reduces the reliability in power system when there is a massive penetration of PV generators. Energy storage systems that are connected to the PV generators using bidirectional isolated dc-dc converter can be utilized for compensating the fluctuating PV power. This paper presents a grid connected energy storage system based on a $2 \mathrm{~kW}$ full-bridge bidirectional isolated dc-dc converter and a PWM converter for PV output power leveling. This paper proposes two controllers: a current controller using the $\mathrm{d}-\mathrm{q}$ synchronous reference and a phase-shift controller. The main function of the current controller is to regulate the voltage at the high-side dc, so that the voltage ratio of the high-voltage side (HVS) with low-voltage side (LVS) is equal to the transformer turns ratio. The phase-shift controller is employed to manage the charging and discharging modes of the battery based on PV output power and battery voltage. With the proposed system, unity power factor and efficient active power injection are achieved. The feasibility of the proposed control system is investigated using PSCAD simulation.
\end{abstract}

\section{Introduction}

Many countries are implementing PV solar panels as they are a clean and sustainable source to meet their power demands. However, the grid connected PV unit without energy storage unit can affect the utility grid in a negative manner due to the intermittent nature of PV. In order to solve this problem, integration of energy storage system to level the output power of PV is necessary [1-4].

There are many types of energy storage systems such as superconducting magnetic energy storage, flywheel, capacitor, battery, and pump hydrostorage. The battery energy storage device is modular, making it easy to be connected close to the point of load and the PV generators. Li-ion batteries have high energy density and are being increasingly used in battery connected PV systems [5]. However, as long as it is employed for PV application, an efficient bidirectional system is required to perform the charging and discharging of the batteries.

Various configuration of a bidirectional isolated dc-dc converter has been investigated in [6]. Bidirectional dc-dc converter can be categorized as isolated and nonisolated topologies. Although an isolated converter is more complicated and expensive than a nonisolated converter, it benefits the system safety, reliability, and flexibility. In addition, the full-bridge topology has a high efficiency, while providing minimum switching loss, improved EMI, and galvanic isolation for energy storage systems. It is also preferred due to its minimal voltage and current stress in high-power applications [7-9]. The bidirectional full-bridge isolated dcdc converter is a reliable system with high efficiency for PV applications in order to remove probable fluctuations and stabilize the PV output.

As Figure 1 shows, typically, a battery energy storage system (BESS) consists of a battery bank, a bidirectional fullbridge isolated dc-dc converter, and a grid connected PWM converter. In addition to the power circuit of the converters, a reliable control system is required for two main purposes. Firstly, it is to manage the power flow in both directions, achieving charging and discharging modes of the battery. Secondly, it is to adjust the voltage of HVS with respect to the voltage of LVS of the converter so that the voltage ratio of the HVS with LVS is close to the transformer turns ratio [10]. The voltage adjustment is necessary to decrease the peak switching current and the turn-off overvoltage across the semiconductor switches.

A $6 \mathrm{~kW}$ bidirectional isolated $\mathrm{dc}-\mathrm{dc}$ converter connecting a Li-ion battery bank to the utility grid via a PWM converter 


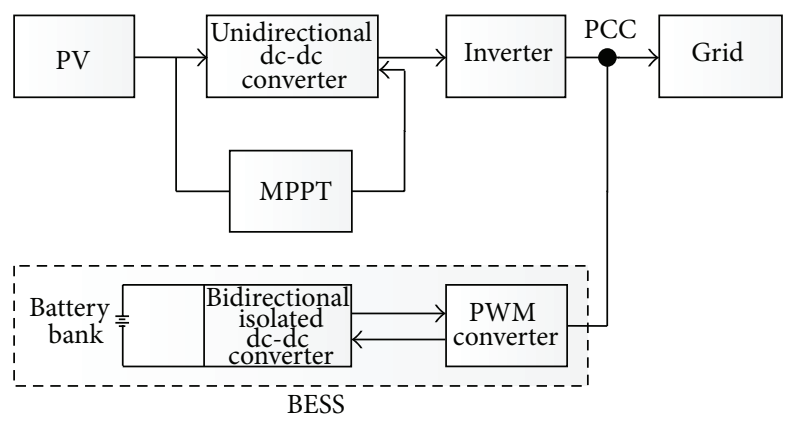

FIGURE 1: Battery energy storage and PV systems connected to the utility grid.

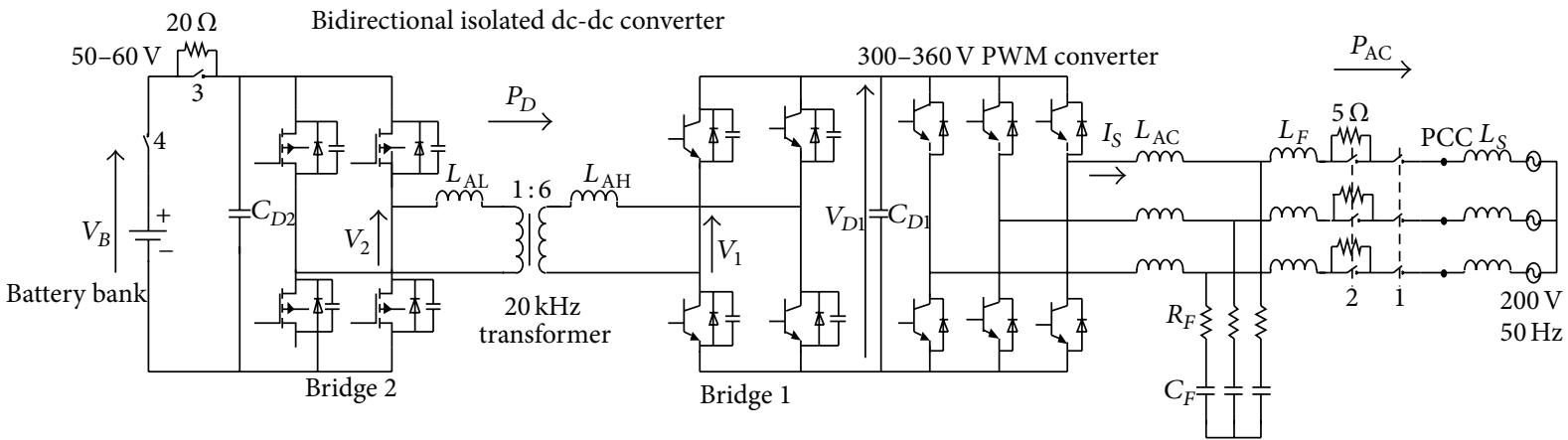

FIGURE 2: The grid-connected BESS based on a bidirectional isolated dc-dc converter. $L_{S}$ is the background system impedance. $L_{\mathrm{AC}}=280 \mu \mathrm{H}$ (0.4\%), $L_{F}=44 \mu \mathrm{H}(0.1 \%), R_{F}=0.2 \Omega(1 \%)$, and $C_{F}=150 \mu \mathrm{F}$, on a three-phase $200 \mathrm{~V}, 2 \mathrm{~kW}$, and $50 \mathrm{~Hz}$ base.

has been presented in $[10,11]$. The paper in [11] mitigated the effects of the dc-bias currents in the high frequency transformer through the design of an air gap in the transformer. The control method employed is feed-forward phase-shift modulation with no online voltage regulation of the HVS. Hence, the voltage ratio of the HVS with LVS was manually controlled so that it is close to the transformer turns ratio.

This paper focuses on the overall control of the BESS which includes the controls of the bidirectional isolated dcdc converter and the PWM converter. This paper proposes two controllers for the BESS. The first part is a feedback controller that regulates the voltage of HVS DC capacitor based on the battery bank voltage and the second part determines the direction and the amount of the required BESS power based on the PV output power and battery bank voltage. Accordingly, while the $2 \mathrm{~kW}$ bidirectional isolated dc-dc converter operates to regulate the power at the PCC, the proposed control system continuously adjusts the voltages of HVS so that the voltage ratio of the HVS with LVS is close to the transformer turns ratio, resulting in increasing the converter efficiency. This paper verifies the proposed BESS for the application of $\mathrm{PV}$ output power leveling via simulation in PSCAD.

\section{Power Circuit Configuration}

Figure 2 shows the battery bank connected at the low-voltage side (LVS) of the $2 \mathrm{~kW}$ dc-dc converter. The PWM converter
TABLE 1: Circuit parameters of the bidirectional isolated dc-dc converter.

\begin{tabular}{lcc}
\hline Rated power & $P_{\mathrm{DC}}$ & $2 \mathrm{~kW}$ \\
Transformer turns ratio & $N: 1$ & $6: 1$ \\
Auxiliary inductor (HVS) & $L_{\mathrm{AH}}$ & $80 \mu \mathrm{H}(15.5 \%)$ \\
Snubber capacitor (HVS) & $C_{\mathrm{SH}}$ & $10 \mathrm{nF}$ \\
DC capacitor (HVS) & $C_{D 1}$ & $1 \mathrm{mF}$ \\
Auxiliary inductor (LVS) & $L_{\mathrm{AL}}$ & $3.5 \mu \mathrm{H}(24.4 \%)$ \\
Snubber capacitor (LVS) & $C_{\mathrm{SL}}$ & $150 \mathrm{nF}$ \\
DC capacitor (LVS) & $C_{D 2}$ & $1 \mathrm{mF}$ \\
Switching frequency & $f$ & $20 \mathrm{kHz}$ \\
\hline
\end{tabular}

HVS is based on $2 \mathrm{~kW}, 360 \mathrm{~V}$, and $20 \mathrm{kHz}$.

LVS is based on $2 \mathrm{~kW}, 60 \mathrm{~V}$, and $20 \mathrm{kHz}$.

interfaces the high-voltage side (HVS) of the dc-dc converter with the utility grid at the PCC via the switching ripple filters and $\mathrm{AC}$ inductors. A $20 \mathrm{kHz}$ high frequency transformer with a turns ratio of $6: 1$ is utilized as it is small in size and light in weight. It also provides galvanic isolation to ensure system safety and reliability. The circuit configuration is similar to that in [10]. However, this paper investigates the feasibility of the system in PV output power leveling via the proposed control system.

Table 1 summarizes the parameters of the circuit in Figure 2. The operating voltage of the battery, $V_{B}$, is set between $50 \mathrm{~V}$ and $60 \mathrm{~V}$ and at the high-voltage side, $V_{D 1}$ is 


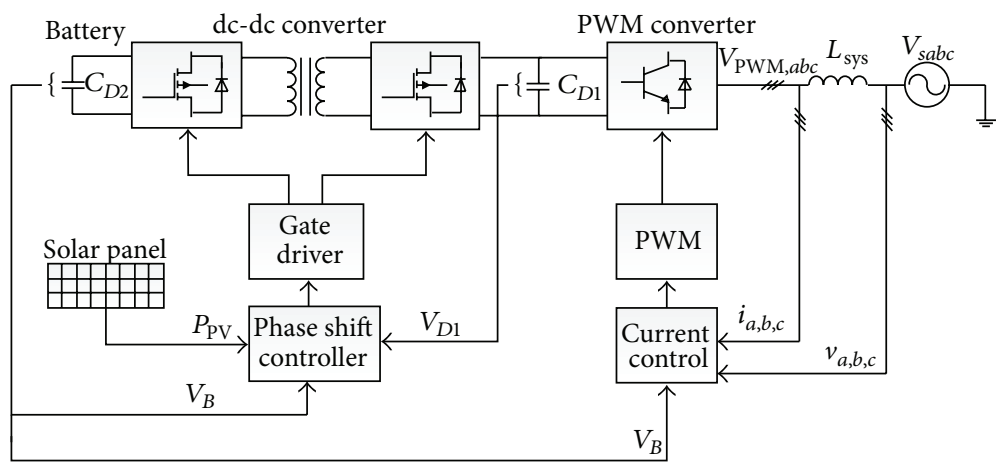

FIGURE 3: Configuration of the proposed control system.

TABLE 2: The gains of the three PI controllers.

\begin{tabular}{lccc}
\hline & $\mathrm{PI}_{1}$ & $\mathrm{PI}_{2}$ & $\mathrm{PI}_{3}$ \\
\hline Proportional gain $K_{p}$ & 0.5 & 0.48 & 0.9 \\
Integral gain $K_{I}$ & 0.03 & 0.25 & 0.04 \\
\hline
\end{tabular}

regulated between $300 \mathrm{~V}$ and $360 \mathrm{~V}$ to maintain the ratio of HVS and LVS close to the transformer turns ratio. The rated voltage of $60 \mathrm{~V}$ is selected taking into consideration user safety. The minimum voltage of $60 \mathrm{~V}$ is based on the specification of Li-ion battery available. The BESS is sized for active power injection at the PCC of up to $2 \mathrm{~kW}$. The power transfer, $P_{D}$, of the bidirectional isolated $\mathrm{dc}$-dc converter can easily be controlled by adjusting the phase-shift angle $\delta$ between two AC voltages $V_{1}$ and $V_{2}$ as expressed as [12]

$$
P_{D}=\frac{V_{D 1} V_{B}}{\omega L} \delta\left(1-\frac{|\delta|}{\pi}\right)
$$

where $V_{D 1}$ is the high-side voltage, $V_{B}$ is the battery voltage at the low-voltage side, $\omega$ is the angular switching frequency, and $L$ is the sum of the transformer leakage and auxiliary inductance referred to as the high-voltage side. In a practical system, the leakage inductance of the high-frequency transformer should be minimized to prevent the so-called spot heating on the transformer. In the simulation system, the leakage inductance of the transformer is neglected.

A start-up circuit, consisting of four circuit breakers, is employed to prevent a large inrush current flow into the $\mathrm{dc}$ capacitors, which will result in saturating the AC inductors in a practical system. Therefore, the start-up procedure is employed to charge capacitors $C_{D 1}$ and $C_{D 2}$ through $5 \Omega$ and $20 \Omega$ resistors connected on the utility and battery sides, respectively.

\section{Overall Control System}

Figure 3 presents the proposed overall control system. The proposed control system regulates the injected power at the PCC to be at $2 \mathrm{~kW}$. The current control technique has been employed to regulate the voltage across dc-link capacitor $C_{D 1}$. Three-phase $d-q$ axis transformation control strategy is employed to regulate the capacitor voltage of the PWM converter, $V_{D 1}$, based on the battery voltage $V_{B}$. In fact, this system monitors $V_{B}$ and keeps $V_{D 1}$ at a level where the voltage ratio between $V_{D 1}$ and $V_{B}$ is close to the transformer turns ratio. On the other hand, the phase shift controller considers output power of $\mathrm{PV}, P_{\mathrm{PV}}$, to determine the desired output power from the BESS such that

$$
P_{\mathrm{BESS}}=P_{\mathrm{PCC}}-P_{\mathrm{PV}} \text {, }
$$

where in this paper $P_{\mathrm{PCC}}=2 \mathrm{~kW}$. The controller also considers the battery voltage, $V_{B}$, and the HVS capacitor voltage, $V_{D 1}$. Then it calculates the new phase shift angle, $\delta$, needed to level the PV output power through battery charging or discharging. Note that for the purpose of simulation, the PV output power is assumed and the modelling of PV generation system is outside the scope of this paper.

Figure 4 shows the verification flow chart of the power management system of the phase-shift controller in the battery energy storage system. The amount of active power required to compensate the $\mathrm{PV}$ output power is calculated by the phase-shift controller. Three PV output power conditions are considered during the operation of the proposed control system. In the first condition, the output power of PV is less than $2 \mathrm{~kW}$. The controller checks the battery voltage to be between $50 \mathrm{~V}$ and $60 \mathrm{~V}\left(50 \mathrm{~V}<V_{B} \leq 60 \mathrm{~V}\right)$. Then the BESS operates in the discharging mode to compensate for the reduced PV output power. In the second condition, the output power of PV is $2 \mathrm{~kW}$. In this case BESS goes to standby mode by changing the phase shift to zero. In the third condition, the output power of PV is more than $2 \mathrm{~kW}$. The controller checks the battery voltage to be less than $60 \mathrm{~V}\left(V_{B}<\right.$ $60 \mathrm{~V}$ ). Then the BESS is charged to absorb the surplus power of PV. As shown in Figure 4, there are two other conditions where the BESS goes on standby mode:

(i) when the battery voltage is less than $50 \mathrm{~V}$ and the $P_{\mathrm{PV}}$ is less than $2 \mathrm{~kW}$,

(ii) when the battery voltage is more than $60 \mathrm{~V}$ and the $P_{\mathrm{PV}}$ is more than $2 \mathrm{~kW}$.

This is to protect the Li-ion battery bank from being overcharged and over discharged [13]. Apart from putting the BESS on standby, the excess power of PV can be discharged through a dump load [14]. 


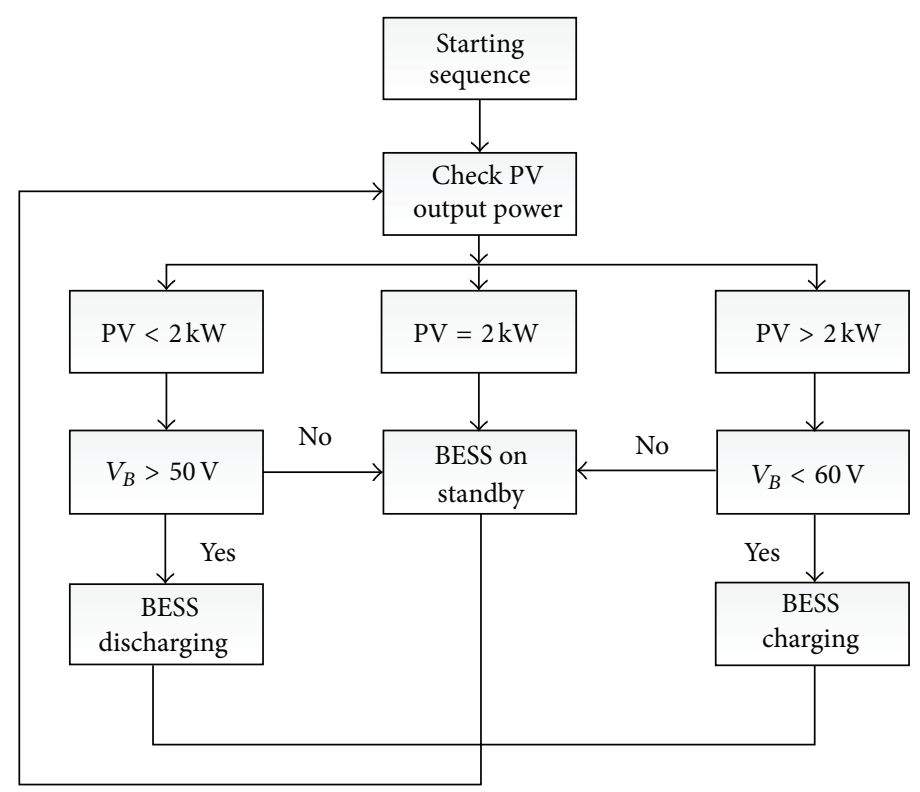

FIGURE 4: The verification flow chart to ascertain the BESS to be in standby, charging, or discharging mode.

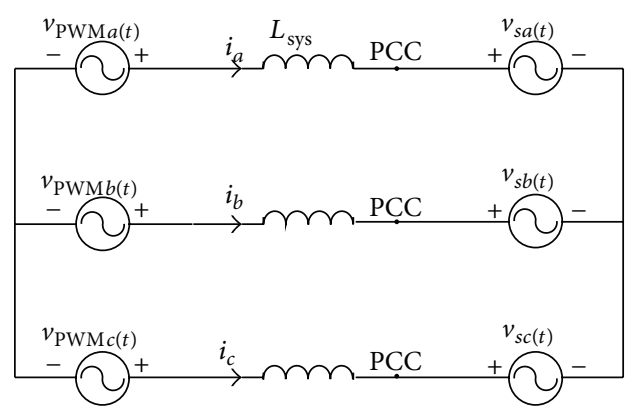

FIGURE 5: Equivalent circuit of the proposed system.

3.1. Control Algorithm of PWM Converter. Figure 5 illustrates the equivalent circuit of PWM converter and grid. The proposed control system regulates the three phase currents, $i_{a}, i_{b}$, and $i_{c}$ to achieve unity power factor and to regulate the dc-link voltage at the PWM converter. A PLL has been employed for providing the grid phase angle information, $\omega t$. The PLL provides fast and accurate synchronization information with a high degree of immunity and insensitivity to disturbances, harmonics, unbalances, sags/swells, notches, and other types of distortions in the input signal. An accurate estimation of utility phase angle is critical for maintaining the power quality at the PCC. The Kirchhoff voltage law (KVL) can be applied to Figure 5, and the three-phase KVL equation is expressed as

$$
L_{\mathrm{sys}} \frac{d}{d t}\left[\begin{array}{l}
i_{a} \\
i_{b} \\
i_{c}
\end{array}\right]=\left[\begin{array}{c}
v_{s a} \\
v_{s b} \\
v_{s c}
\end{array}\right]-\left[\begin{array}{c}
v_{\mathrm{PWM} a} \\
v_{\mathrm{PWM} b} \\
v_{\mathrm{PWM} c}
\end{array}\right],
$$

where $v_{s}$ is the three-phase voltage at the PCC, $L_{\text {sys }}\left(L_{\mathrm{AC}}+\right.$ $\left.L_{F}+L_{S}\right)$ is the total per phase series inductance, and $v_{\mathrm{PWM}}$ is the three-phase output voltage of the PWM converter. The supply voltage can be defined as

$$
\left[\begin{array}{c}
v_{s a} \\
v_{s b} \\
v_{s c}
\end{array}\right]=\widehat{V}\left[\begin{array}{c}
\cos \omega t \\
\cos (\omega t-\theta) \\
\cos (\omega t+\theta)
\end{array}\right]
$$

where $\widehat{V}$ is the magnitude of the voltage at the PCC, $\omega t$ is the phase angle, and $\theta$ is $2 \pi / 3$ for a balanced three-phase system. The proposed control system is based on the $d$ $q$ transformation method. The $d$ and $q$ components of the three-phase current $i_{a}$, $i_{b}$, and $i_{c}$ are obtained using Park's transformation through the transformation matrix,

$$
P=\frac{2}{3}\left[\begin{array}{ccc}
\cos \omega t & \cos \left(\omega t-\frac{2 \pi}{3}\right) & \cos \left(\omega t+\frac{2 \pi}{3}\right) \\
\sin \omega t & \sin \left(\omega t-\frac{2 \pi}{3}\right) & \sin \left(\omega t+\frac{2 \pi}{3}\right) \\
\frac{1}{2} & \frac{1}{2} & \frac{1}{2}
\end{array}\right] .
$$

The inverse of the Park's transformation matrix is defined as

$$
P^{-1}=\left[\begin{array}{ccc}
\cos \omega t & \sin \omega t & 1 \\
\cos \left(\omega t-\frac{2 \pi}{3}\right) & \sin \left(\omega t-\frac{2 \pi}{3}\right) & 1 \\
\cos \left(\omega t+\frac{2 \pi}{3}\right) & \sin \left(\omega t+\frac{2 \pi}{3}\right) & 1
\end{array}\right] .
$$

Using (5) and (6), equation (3) can be rewritten as

$$
P * L_{\text {sys }} * \frac{d}{d t} P^{-1}\left[\begin{array}{c}
I_{d} \\
I_{q} \\
I_{0}
\end{array}\right]=P P^{-1}\left[\begin{array}{c}
V_{s d} \\
V_{s q} \\
V_{s 0}
\end{array}\right]-P P^{-1}\left[\begin{array}{c}
V_{\mathrm{PWM} d} \\
V_{\mathrm{PWM} q} \\
V_{\mathrm{PWM} 0}
\end{array}\right] .
$$




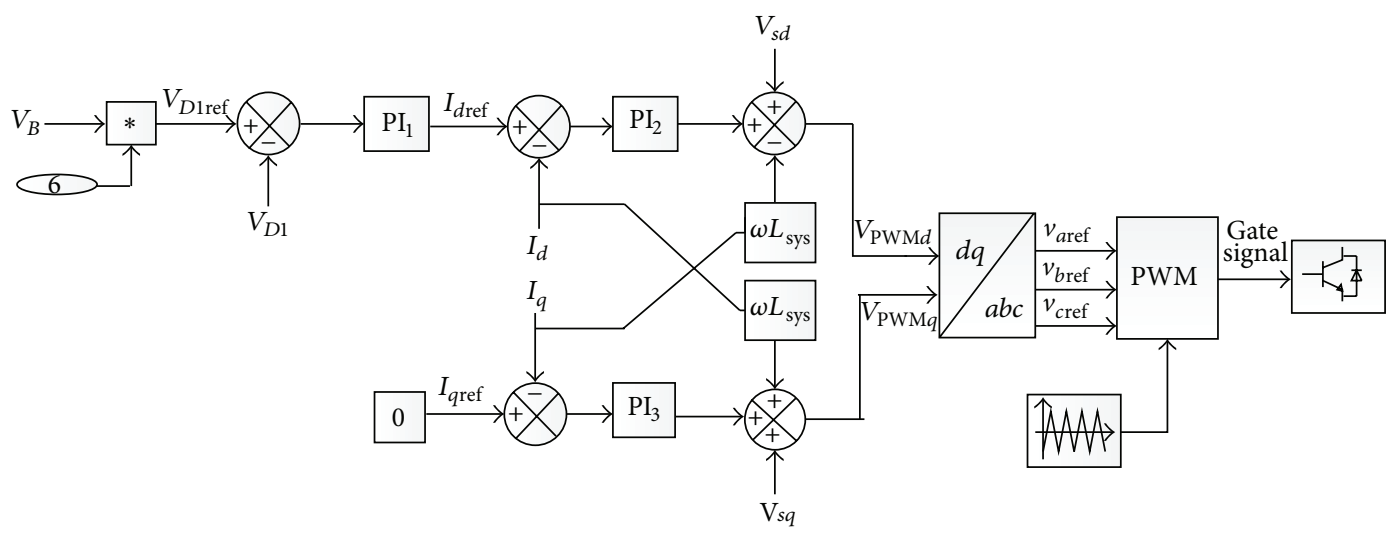

FIGURE 6: Current control of the PWM converter.

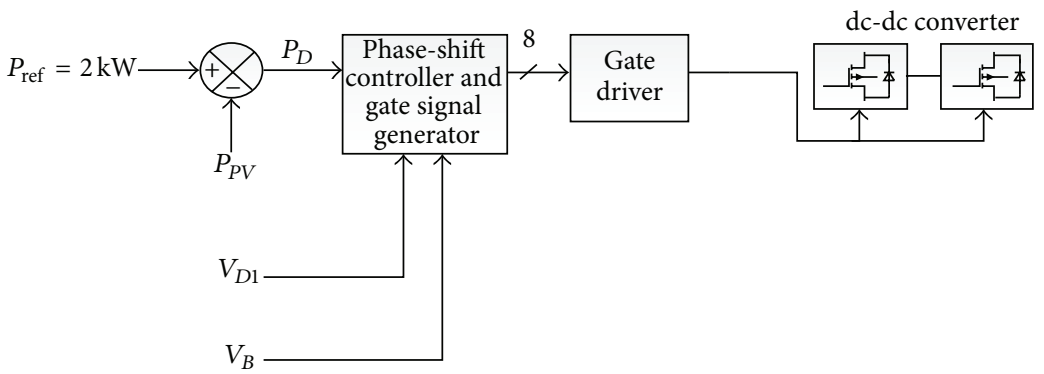

FIGURE 7: Phase shift angle control of the bidirectional isolated dc-dc.

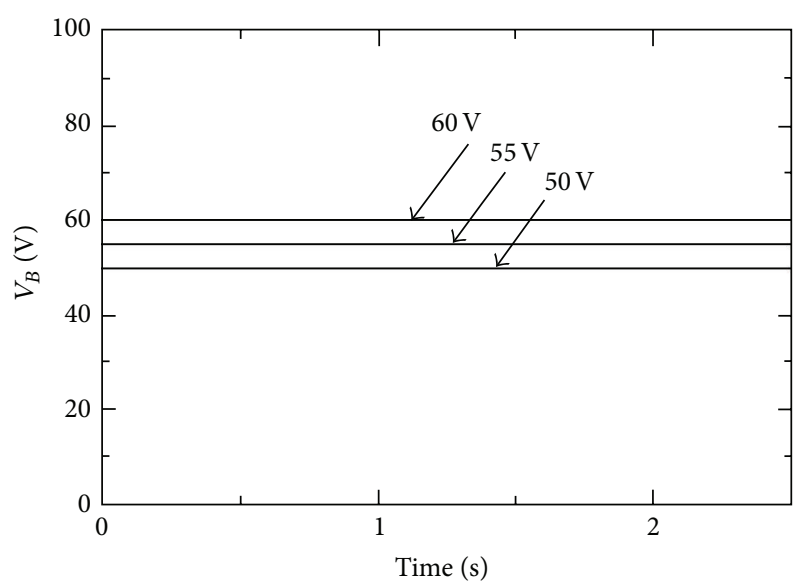

Figure 8: Battery voltage at $50 \mathrm{~V}, 55 \mathrm{~V}$, and $60 \mathrm{~V}$.

In a balance system, the zero sequence component is equivalent to zero and can be omitted, resulting in

$$
\begin{aligned}
\frac{d}{d t}\left[\begin{array}{c}
I_{d} \\
I_{q}
\end{array}\right]= & {\left[\begin{array}{cc}
0 & -\omega \\
\omega & 0
\end{array}\right]\left[\begin{array}{c}
I_{d} \\
I_{q}
\end{array}\right]+\left[\begin{array}{cc}
\frac{1}{L_{\text {sys }}} & 0 \\
0 & \frac{1}{L_{\text {sys }}}
\end{array}\right]\left[\begin{array}{c}
V_{s d} \\
V_{s q}
\end{array}\right] } \\
& -\left[\begin{array}{cc}
\frac{1}{L_{\text {sys }}} & 0 \\
0 & \frac{1}{L_{\text {sys }}}
\end{array}\right]\left[\begin{array}{l}
V_{\mathrm{PWMd}} \\
V_{\mathrm{PWM} q}
\end{array}\right]
\end{aligned}
$$

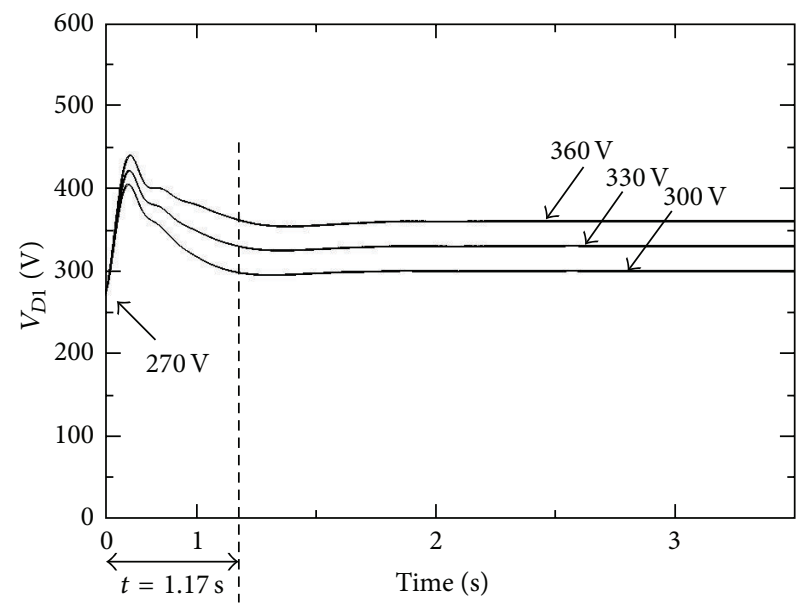

FIGURE 9: The HVS capacitor voltage, $V_{D 1}$, regulated at $300 \mathrm{~V}, 330 \mathrm{~V}$, and $360 \mathrm{~V}$.

Equation (8) can be divided into

$$
\begin{gathered}
\frac{d I_{d}}{d t}=-\omega I_{q}+\frac{V_{s d}}{L_{\text {sys }}}-\frac{V_{\mathrm{PWM} d}}{L_{\mathrm{sys}}}, \\
\frac{d I_{q}}{d t}=\omega I_{d}+\frac{V_{s q}}{L_{\text {sys }}}-\frac{V_{\mathrm{PWMq}}}{L_{\text {sys }}} .
\end{gathered}
$$




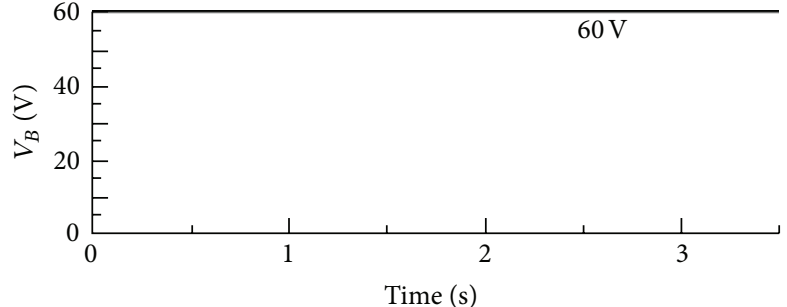

(a)

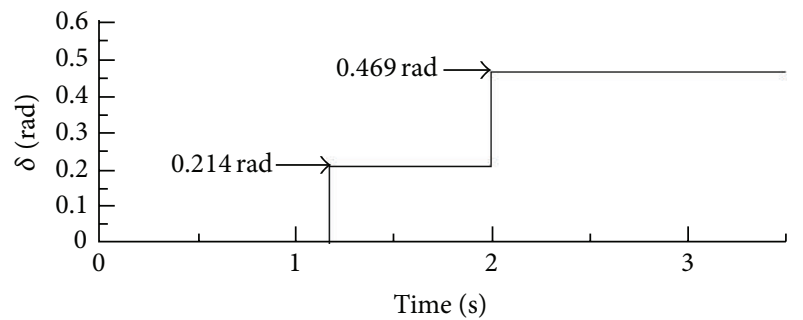

(c)

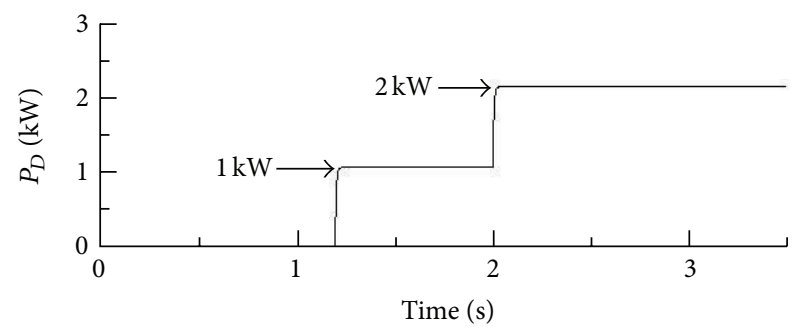

(e)

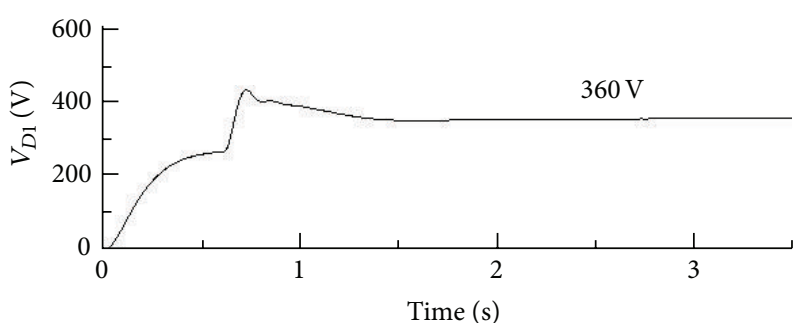

(b)

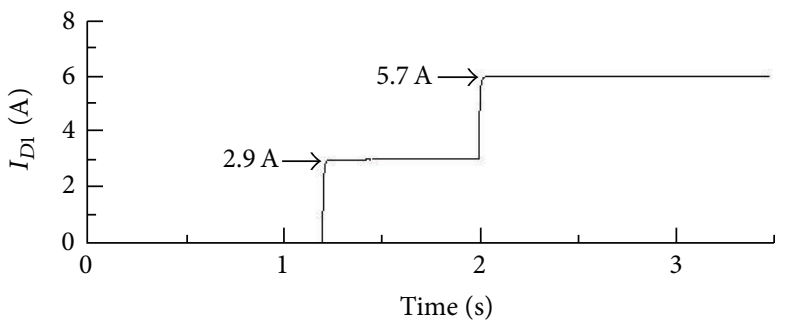

(d)

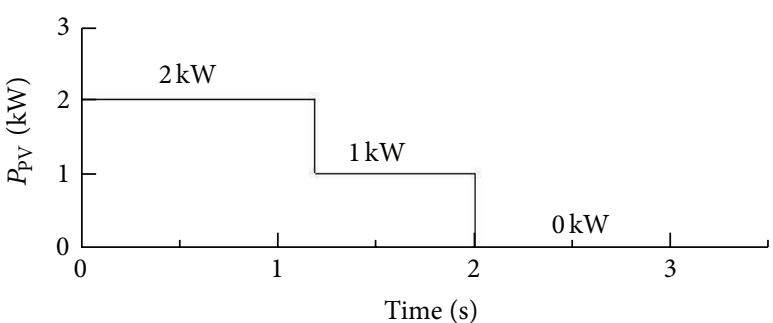

(f)

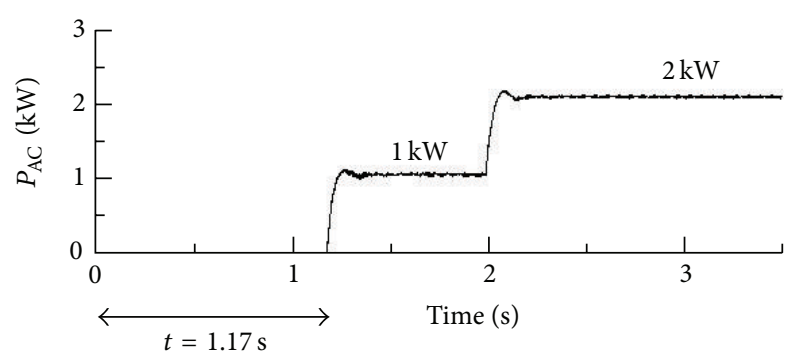

(g)

FIGURE 10: Simulation waveforms of the step PV output change from $2 \mathrm{~kW}$ to $0 \mathrm{~kW}$. (a) Battery voltage. (b) High-voltage-side capacitor voltage. (c) Phase-shift angle. (d) High-side dc current. (e) BESS DC power. (f) PV output power. (g) BESS AC output power.

The steady-state condition is achieved when the derivative terms of $d I_{d} / d t$ and $d I_{q} / d t$ are equal to zero. Then $V_{\mathrm{PWM}}$ and $V_{\mathrm{PWMq}}$ can be obtained as

$$
\begin{gathered}
V_{\mathrm{PWM} d}=-\omega L_{\text {sys }} I_{q}+V_{s d}, \\
V_{\mathrm{PWMq}}=\omega L_{\text {sys }} I_{d}+V_{s q} .
\end{gathered}
$$

Equations (10) are implemented as part of the control in Figure 6. The goal of the control system is to regulate the voltage of HVS dc-link capacitor, $V_{D 1}$, by controlling the line currents, $i_{a}, i_{b}$, and $i_{c}$. To generate the reference direct component of current, $I_{d \mathrm{ref}}$, the instantaneous battery voltage $V_{B}$ is multiplied by the transformer turns ratio and is compared with the HVS capacitor voltage $V_{D 1}$. Then the error is passed through a proportional-integral controller, $\mathrm{PI}_{1}$. Therefore, the reference direct component of current is calculated as

$$
I_{d \mathrm{ref}}=\left\{V_{D 1 \mathrm{ref}}-V_{D 1}\right\}\left(K_{P 1}+\int K_{I 1} d_{t}\right) .
$$

The quadrature reference current, $I_{\text {qref }}$ is set at zero to avoid any reactive power transfer. These two references are compared with the actual values of $I_{d}$ and $I_{q}$ and the differences are passed through two PI controllers, $\mathrm{PI}_{2}$ and $\mathrm{PI}_{3}$. The outputs of PI controllers are added with measured $V_{s d}$ and $V_{s q}$, based on (10) for achieving $V_{\mathrm{PWM} d}$ and $V_{\mathrm{PWM}}$. The proportional-integral controllers $\mathrm{PI}_{2}$ and $\mathrm{PI}_{3}$ transform 


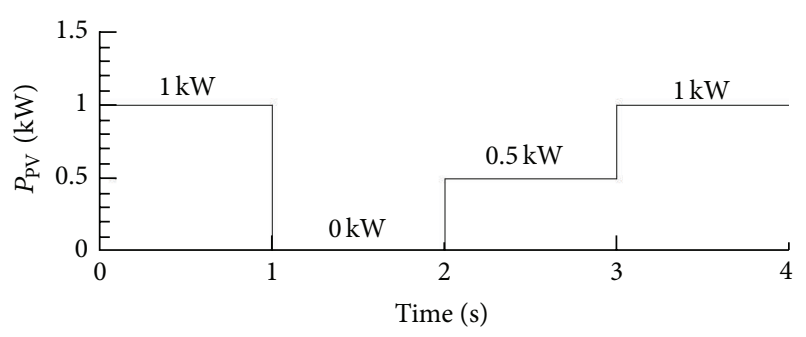

(a)

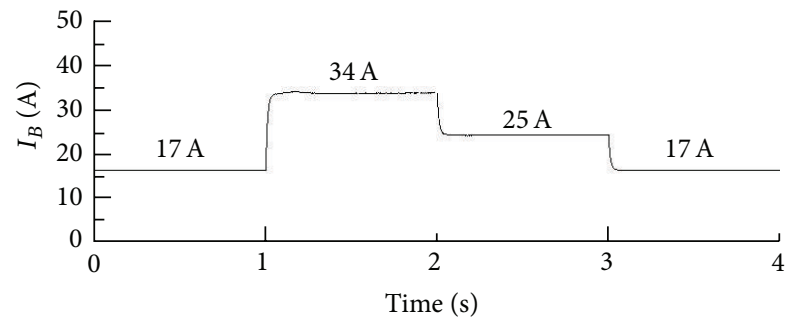

(c)

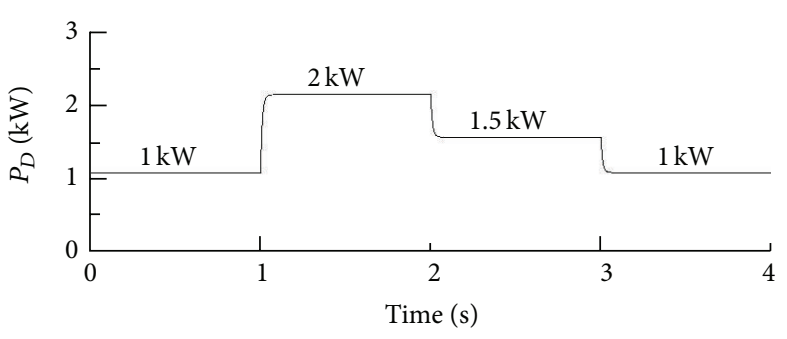

(b)

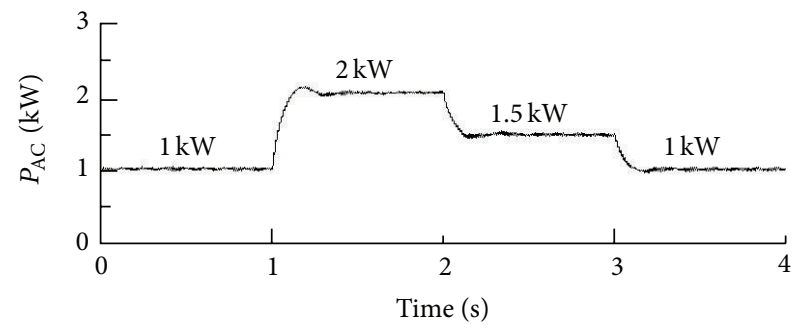

(d)

Figure 11: BESS response at $V_{B}=55 \mathrm{~V}$. (a) PV output power. (b) BESS DC power. (c) Battery current. (d) BESS AC output power.

the errors from the comparisons of $d-q$ components of current into voltage value as

$$
\begin{gathered}
V_{\mathrm{PWM} d}=\left\{I_{d \mathrm{ref}}-I_{d}\right\}\left(K_{p 2}+\frac{K_{I 2}}{s}\right)-\omega L_{\mathrm{sys}} I_{q}+V_{s d}, \\
V_{\mathrm{PWM} q}=\left\{0-I_{q}\right\}\left(K_{p 3}+\frac{K_{I 3}}{s}\right)+\omega L_{\mathrm{sys}} I_{d}+V_{s q},
\end{gathered}
$$

where $V_{s d}$ is the measured magnitude of the grid voltage and $V_{s q}$ is almost zero. The gain from $\omega L_{\text {sys }}$ is considered to provide the decoupling terms. The parameters $K_{p}$ and $K_{I}$ are tuned by trial and error method. Table 2 presents the parameter of each PI controller. Finally, the dq reference voltages are transformed to $v_{\text {aref }}, v_{b \text { ref }}$, and $v_{c r e f}$ which are the sinusoidal reference voltages of the PWM generator.

\subsection{Control Algorithm of the Bidirectional Isolated dc-dc Con-} verter. Figure 7 shows the control system of the bidirectional isolated dc-dc converter. The battery is charged or discharged through the bidirectional isolated dc-dc converter connected to the PWM converter. Based on this concept, the control system determines the desired BESS power as in (2) in order to regulate the injected power at the PCC at $2 \mathrm{~kW}$ as the PV output power varies. The battery power is assumed to be equal to the power transfer $P_{D}$. The measured values of $P_{\mathrm{PV}}, V_{D 1}$, and $V_{B}$ are employed to compute the phase-shift angle $\delta$ for the required battery charging power as

$$
\delta=\frac{\pi}{2}-\sqrt{\frac{\pi^{2}}{4}-\frac{\omega \pi L P_{D}}{V_{D 1} V_{B} N}}
$$

\begin{tabular}{|c|c|c|c|c|}
\hline $\begin{array}{l}\text { HVS dc-link capacitor } \\
\text { voltage }\end{array}$ & $\begin{array}{c}\text { Breaker } \\
1 \\
\end{array}$ & $\begin{array}{c}\text { Breaker } \\
2 \\
\end{array}$ & $\begin{array}{c}\text { Breaker } \\
3 \\
\end{array}$ & $\begin{array}{c}\text { Breaker } \\
4 \\
\end{array}$ \\
\hline$V_{D 2}<270 \mathrm{~V}$ & Close & Open & Open & Close \\
\hline $270 \mathrm{~V} \leq V_{D 2}<360 \mathrm{~V}$ & Close & Close & Open & Close \\
\hline$V_{D 2}=360 \mathrm{~V}$ & Close & Close & Close & Close \\
\hline
\end{tabular}

TABLE 3: Breaker operations during startup.

and the phase-shift angle for the required battery discharging power as

$$
\delta=-\frac{\pi}{2}+\sqrt{\frac{\pi^{2}}{4}+\frac{\omega \pi L P_{D}}{V_{D 1} V_{B} N}} .
$$

In the phase-shift controller block, it generates 8 gate signals for the gate driver. The gate driver amplifies the signals and sends it to the full bridge converter.

3.3. Simulation Method. A simulation model with the control system is built using PSCAD based on Figures 2 and 3. The circuit parameters and gains in Tables 1 and 2 are used, respectively. The rated output power of the BESS is $2 \mathrm{~kW}$, for a PV generation system rated at $2 \mathrm{~kW}$. The rms voltage of the grid is $200 \mathrm{~V}$ and its rated frequency is $50 \mathrm{~Hz}$. The switching frequency of the PWM converter is $10 \mathrm{kHz}$ and for the bidirectional isolated $\mathrm{dc}-\mathrm{dc}$ converter it is $20 \mathrm{kHz}$. The simulation duration is $3.5 \mathrm{~s}$ and the time step is $0.3 \mu \mathrm{s}$.

Table 3 shows the operating sequence of the circuit breakers during startup. When the charging or discharging mode begins, the startup control circuit closes circuit breakers 1 and 4 . The voltage across the high-voltage capacitor, $V_{D 1}$, increases and stabilizes at $270 \mathrm{~V}$ causing circuit breaker 2 to operate. Then, the control system starts to regulate $V_{D 1}$ to 


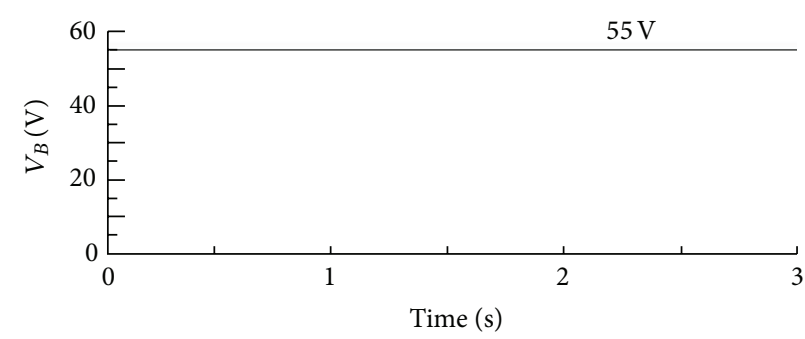

(a)

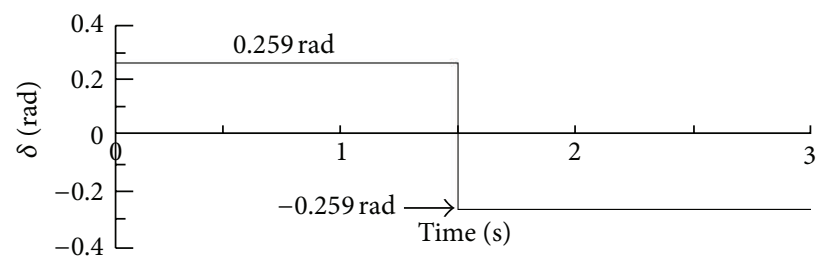

(c)

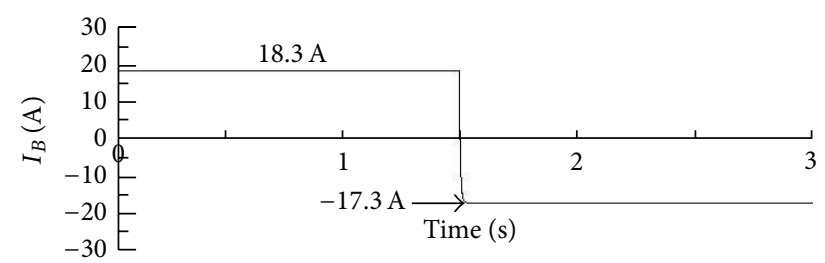

(e)

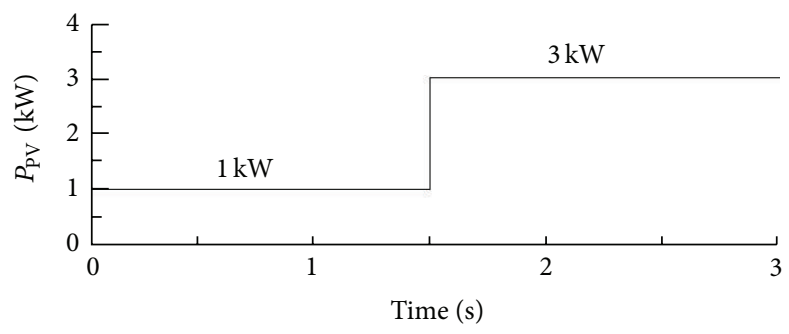

(g)

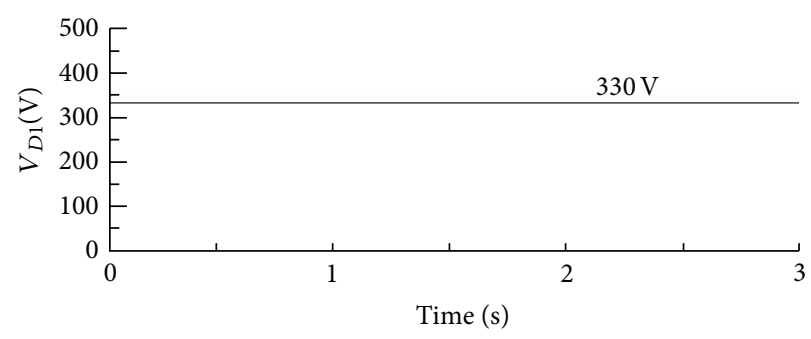

(b)

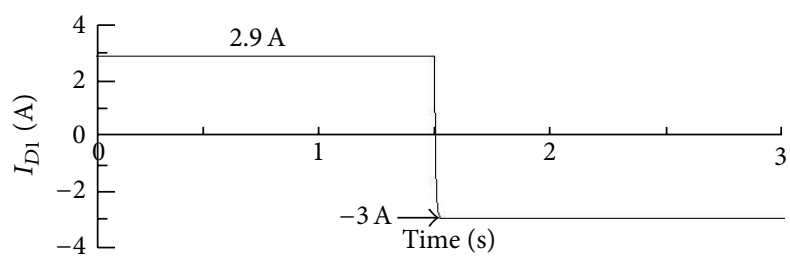

(d)

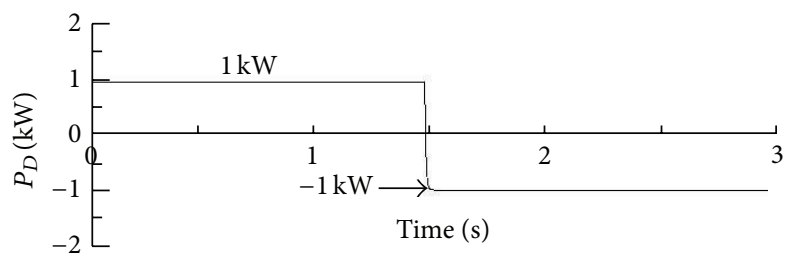

(f)

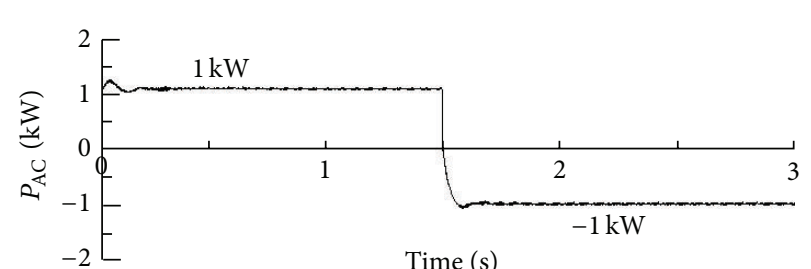

(h)

Figure 12: Simulation waveforms of the step PV output change from $1 \mathrm{~kW}$ to $3 \mathrm{~kW}$. (a) Battery voltage. (b) High voltage side capacitor voltage. (c) Phase shift angle. (d) High-side dc current. (e) Battery current. (f) BESS DC power. (g) PV output power. (h) BESS AC output power.

$360 \mathrm{~V}$, provided that the battery voltage is $60 \mathrm{~V}$. As soon as $V_{D 1}$ is adjusted at $360 \mathrm{~V}$, circuit breaker 3 will be closed and the BESS will operate as per the requirement of the system.

\section{Simulation Waveforms}

Figure 8 illustrates the battery voltage at $60 \mathrm{~V}, 55 \mathrm{~V}$, and $50 \mathrm{~V}$. Figure 9 shows that the capacitor voltage $V_{D 1}$ is regulated to $360 \mathrm{~V}, 330 \mathrm{~V}$, and $300 \mathrm{~V}$ to correspond to the change in the battery voltage. The initial voltage of $V_{D 1}$ is $270 \mathrm{~V}$ because of the start-up sequence. The total duration for the start-up sequence to charge $V_{D 1}$ from 0 to $270 \mathrm{~V}$ is $1.17 \mathrm{~s}$. The start-up sequence only occurs once at the beginning. When the BESS is in the standby mode, no start-up sequence is required.

Figure 10 illustrates the operation of the BESS with varying PV output power. The simulation assumes that the battery voltage is constant at $60 \mathrm{~V}$ and subsequently voltage $V_{D 1}$ is regulated at $360 \mathrm{~V}$ by operation of the control system.
The output power of $P_{\mathrm{PV}}$ is $2 \mathrm{~kW}$ at $t=0 \mathrm{~s}$. The BESS start-up circuit operates and the voltage of HVS capacitor is regulated to $360 \mathrm{~V}$ in $1.17 \mathrm{~s}$. Therefore, the output power from the BESS is equal to zero in this period. At $t=1.17 \mathrm{~s} P_{\mathrm{PV}}=1 \mathrm{~kW}$, phase-shift angle $\delta$ is increased from 0 to $0.214 \mathrm{rad}$, so that $P_{D}=1 \mathrm{~kW}$ to mitigate the power at the $P_{\mathrm{PCC}}$ to $2 \mathrm{~kW}$. At $t=2 \mathrm{~s}$, the PV is not injecting any power and phase-shift angle is increased to $0.469 \mathrm{rad}$. Therefore, the BESS transfers $2 \mathrm{~kW}$ to the PCC.

Figure 11 illustrates the operation of the BESS during changes of the solar output power. Four step changes have been employed. The battery voltage is assumed to be constant at $55 \mathrm{~V}$. The BESS provides $1 \mathrm{~kW}$ from $t=0 \mathrm{~s}$ to $t=1 \mathrm{~s}$. The BESS transfers $2 \mathrm{~kW}$ from $t=1 \mathrm{~s}$ to $t=2 \mathrm{~s}$, between $t=2 \mathrm{~s}$ and $t=3 \mathrm{~s}$, it transfers $1.5 \mathrm{~kW}$, and between $t=3 \mathrm{~s}$ and $t=4 \mathrm{~s}$ it provides $1 \mathrm{~kW}$ to level the PV output power at the PCC.

Figure 12 presents the operation of the BESS during both charging and discharging modes. The simulation assumes 


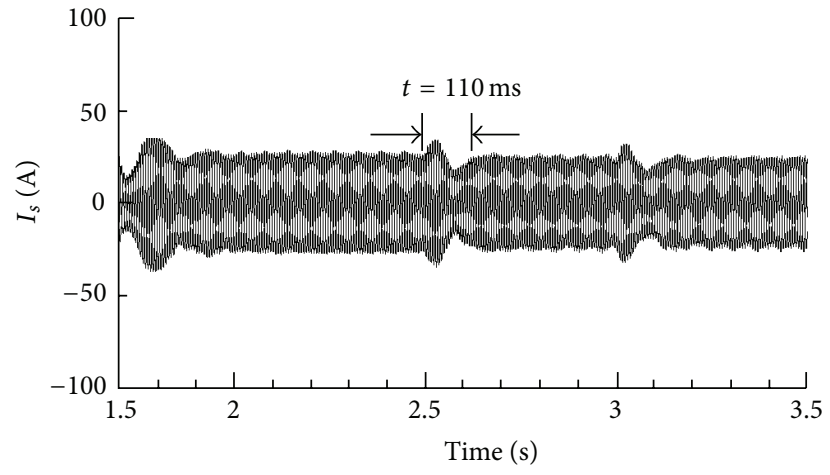

(a)

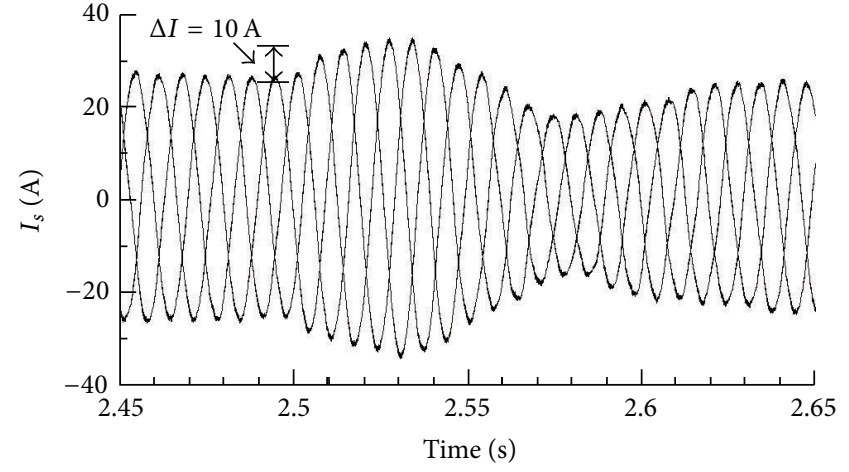

(b)

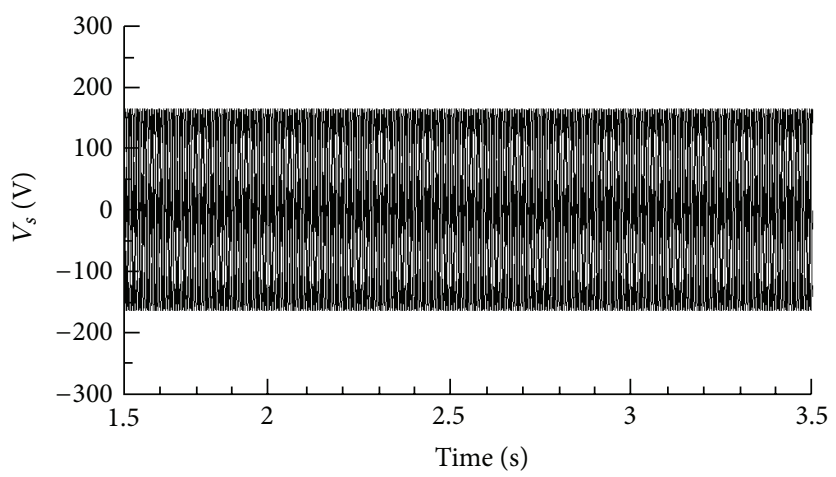

(c)

FIgURE 13: (a) Three-phase AC current. (b) Enlarged waveform of the three-phase AC current during a transient condition. (c) Three-phase AC voltage.

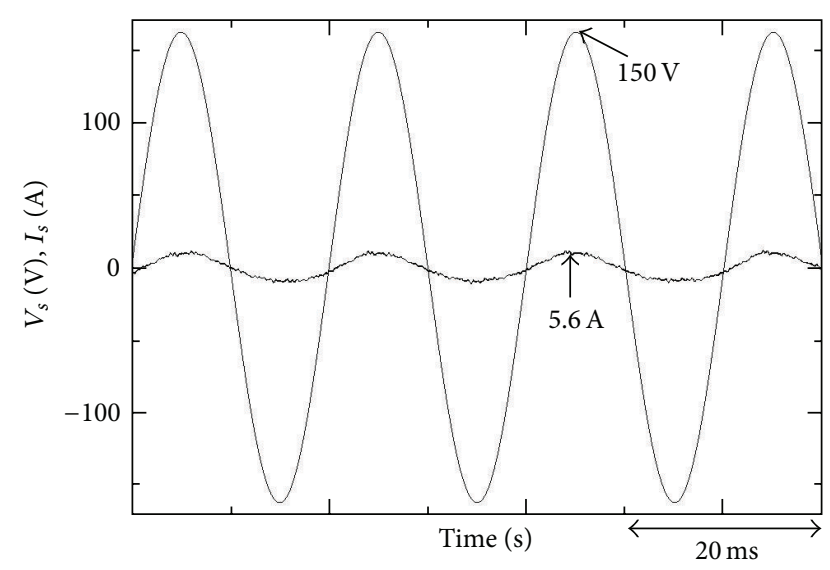

FIGURE 14: AC voltage and current of phase A during the operation of the BESS.

that the battery voltage is constant at $55 \mathrm{~V}$. Between $t=0 \mathrm{~s}$ and $t=1.5 \mathrm{~s}$, the $\mathrm{PV}$ is producing $P_{\mathrm{PV}}=1 \mathrm{~kW}$. The controller of the BESS detects the power which is less than $2 \mathrm{~kW}$. Therefore, the BESS operates to discharge the battery by changing $\delta$ from 0 to $0.259 \mathrm{rad}$, so that the BESS discharges power of $1 \mathrm{~kW}$ and mitigates the power at the $P_{\mathrm{PCC}}$ to $2 \mathrm{~kW}$. Between $t=1.5 \mathrm{~s}$ and $t=3 \mathrm{~s}$, the output of PV increases to $3 \mathrm{~kW}$. In this mode, the control system detects the output of PV that exceeded
$2 \mathrm{~kW}$ and battery voltage which is less than $60 \mathrm{~V}$. Therefore, it changes the direction of power and charges the battery bank. So that $P_{D}=-1 \mathrm{~kW}$ to mitigate the power at the $P_{\mathrm{PCC}}$ to $2 \mathrm{~kW}$. When the battery voltage is $60 \mathrm{~V}$, the BESS will go on standby mode.

Figure 13(a) presents the three phase AC current during the operation of the control system. Figure 13(b) shows the transient of the AC current. The transient lasted for $110 \mathrm{~ms}$ and the peak of the transient current is $10 \mathrm{~A}$. Figure 13(c) shows the AC output voltage of the BESS. The THD of voltage during charging of the $C_{D 1}$ is around $0.7 \%$ and during the discharging operation of the $\mathrm{dc}-\mathrm{dc}$ converter the THD it is negligible.

Figure 14 shows the AC voltage and AC current during the operation of the BESS at the rated power $2 \mathrm{~kW}$ and battery voltage $60 \mathrm{~V}$. The synchronized voltage and current waveforms show that the power factor is unity. As explained in Section 3 , the control system converges $I_{q}$ to zero. Therefore, the system works with unity power factor.

Figure 15 shows the AC voltage and current waveforms at the HVS and LVS of the transformer when the power transfer is changed from $1 \mathrm{~kW}$ to $2 \mathrm{~kW}$. There are changes to the phase-shift angles from $0.214 \mathrm{rad}$ to $0.504 \mathrm{rad}$ during the change in power transfer requirement. The input and output voltages of transformer are close to the transformer turns ratio. Figure 15(c) shows flat top current. It reduces the rate of change of currents $I_{1}$ and $I_{2}$ over the time interval 


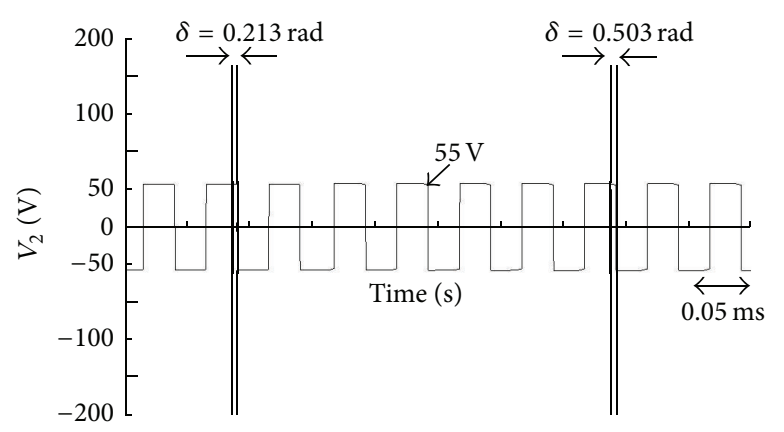

(a)

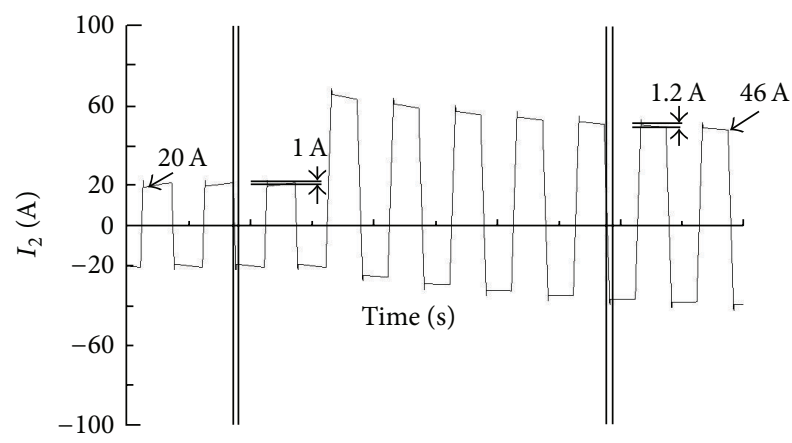

(c)

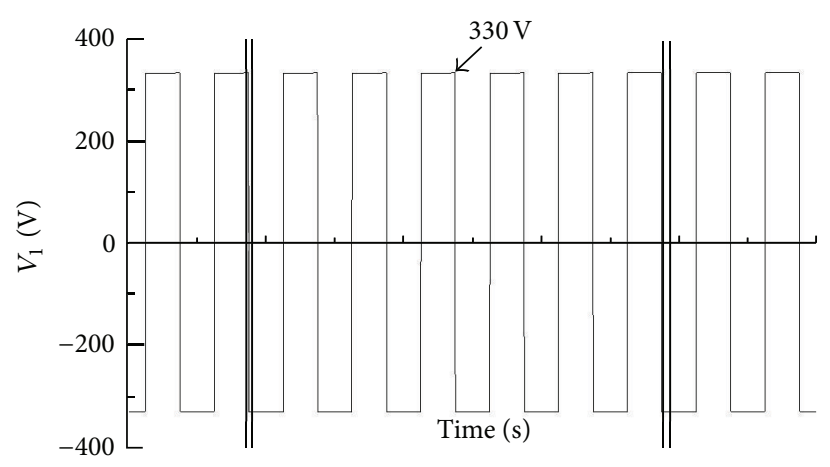

(b)

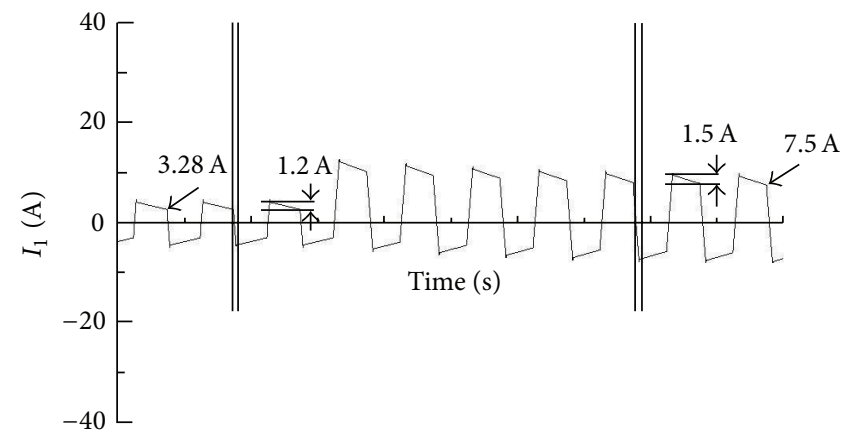

(d)

FIGURE 15: Operation of the phase shift controller during changing power from $1 \mathrm{~kW}$ to $2 \mathrm{~kW}$ at $V_{2}=55 \mathrm{~V}$ and $V_{1}=330 \mathrm{~V}$ for a duration of 1.7 s. (a) Low-side transformer voltage. (b) High-side transformer voltage side voltage. (c) Low-voltage-side current. (d) High-voltage-side current.

of conduction. Thus, this will minimize the peak switching current which causes a higher switch turn-off overvoltage and improve converter efficiency.

\section{Conclusion}

The proposed controller that regulates the HVS dc-link capacitor voltage is successful in ensuring that the voltage ratio between the HVS and LVS is close to the transformer turns ratio. This strategy increases the efficiency of the system by minimising the switching current in the dc-dc converter. Unity power factor is also achieved during battery charging and discharging at the utility side. The feasibility of the controller in injecting the required power at the PCC to level the PV output power has been verified via simulation.

\section{Conflict of Interests}

The authors declare that there is no conflict of interests regarding the publication of this paper.

\section{Acknowledgment}

The authors wish to acknowledge the financial support for this project from the Ministry of Higher Education (MOHE) of Malaysia under the Fundamental Research Grant Scheme (FRGS), project number FRGS/1/2012/TK07/UNITEN/02/11.

\section{References}

[1] S. C. Smith, P. K. Sen, and B. Kroposki, "Advancement of energy storage devices and applications in electrical power system," in Proceedings of the IEEE Power and Energy Society General Meeting: Conversion and Delivery of Electrical Energy in the 21st Century (PES '08), pp. 1-8, Pittsburgh, Pa, USA, July 2008.

[2] M. Datta, T. Senjyu, A. Yona, and T. Funabashi, "Photovoltaic output power fluctuations smoothing by selecting optimal capacity of battery for a photovoltaic-diesel hybrid system," Electric Power Components and Systems, vol. 39, no. 7, pp. 621644, 2011.

[3] N. H. Samrat, N. B. Ahmad, I. A. Choudhury, and Z. B. Taha, "Modeling, control, and simulation of battery storage photovoltaic-wave energy hybrid renewable power generation systems for island electrification in malaysia," Scientific World Journal, vol. 2014, Article ID 436376, 21 pages, 2014.

[4] A. Solanki, L. F. Montoya, Q. Fu et al., "Managing intermittent renewables in a microgrid," in Proceedings of the IEEE PES Innovative Smart Grid Technologies (ISGT '12), pp. 1-6, January 2012.

[5] A. Nadkarni, G. G. Karady, and K. Alteneder, "Investigation of lithium-ion battery cycling in a grid-tied rooftop PV system through accelerated testing," in Proceedings of the IEEE PES Innovative Smart Grid Technologies Conference (ISGT '13), pp. 1-6, February 2013.

[6] N. M. L. Tan, T. Abe, and H. Akagi, "Topology and application of bidirectional isolated dc-dc converters," in Proceedings of the 8th International Conference on Power Electronics-ECCE Asia: 
“Green World with Power Electronics" (ICPE-ECCE '11), pp. 1039-1046, Jeju Island, Republic of Korea, June 2011.

[7] R. L. Steigerwald, R. W. de Doncker, and M. H. Kheraluwala, "Comparison of high power DC-to-DC soft-switched converter topologies," in Proceedings of the 29th IAS Annual Meeting, pp. 1090-1096, October 1994.

[8] H. Tao, A. Kotsopoulos, J. L. Duarte, and M. A. M. Hendrix, "Transformer-coupled multiport ZVS bidirectional DC-DC converter with wide input range," IEEE Transactions on Power Electronics, vol. 23, no. 2, pp. 771-781, 2008.

[9] C. Zhao, S. D. Round, and J. W. Kolar, "An isolated threeport bidirectional dc-dc converter with decoupled power flow management," IEEE Transactions on Power Electronics, vol. 23, no. 5, pp. 2443-2453, 2008.

[10] N. M. L. Tan, T. Abe, and H. Akagi, "A 6-kW, 2-kWh lithiumion battery energy storage system using a bidirectional isolated dc-dc converter," in Proceedings of the International Power Electronics Conference (IPEC '10), pp. 46-52, June 2010.

[11] N. M. L. Tan, T. Abe, and H. Akagi, "Design and performance of a bidirectional isolated DC-DC converter for a battery energy storage system," IEEE Transactions on Power Electronics, vol. 27, no. 3, pp. 1237-1248, 2012.

[12] R. W. de Doncker, D. M. Divan, and M. H. Kheraluwala, "A three-phase soft-switched high-power-density DC/DC converter for high-power applications," IEEE Transactions on Industry Applications, vol. 27, no. 1, pp. 63-73, 1991.

[13] K. Ravichandrudu, S. Fathima, M. P. Y. Babu, and M. G. Anjaneyulu, "Design and performance of a bidirectional isolated Dc-Dc converter for renewable power system," Journal of Electrical and Electronics Engineering, vol. 7, pp. 81-87, 2013.

[14] N. Mendis, K. M. Muttaqi, S. Sayeef, and S. Perera, "Application of a hybrid energy storage in a remote area power supply system," in Proceedings of the IEEE International Energy Conference and Exhibition (EnergyCon '10), pp. 576-581, December 2010. 

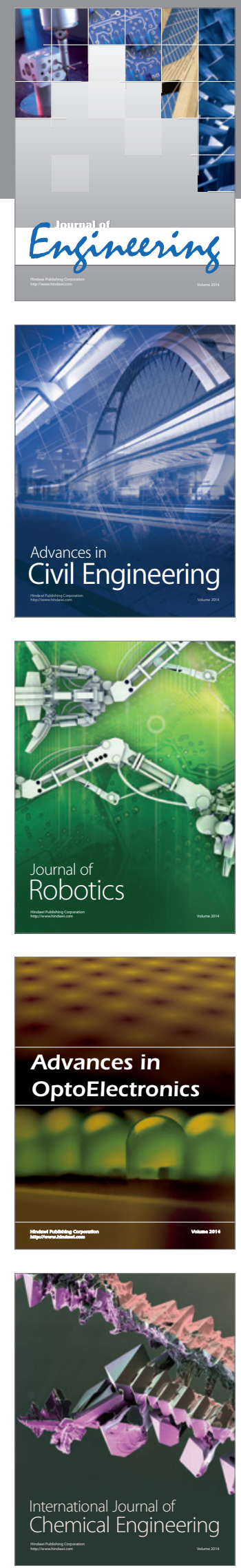

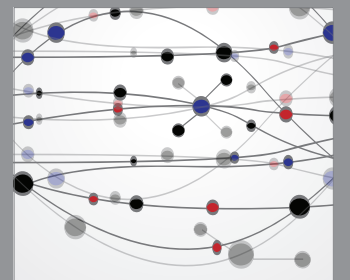

The Scientific World Journal
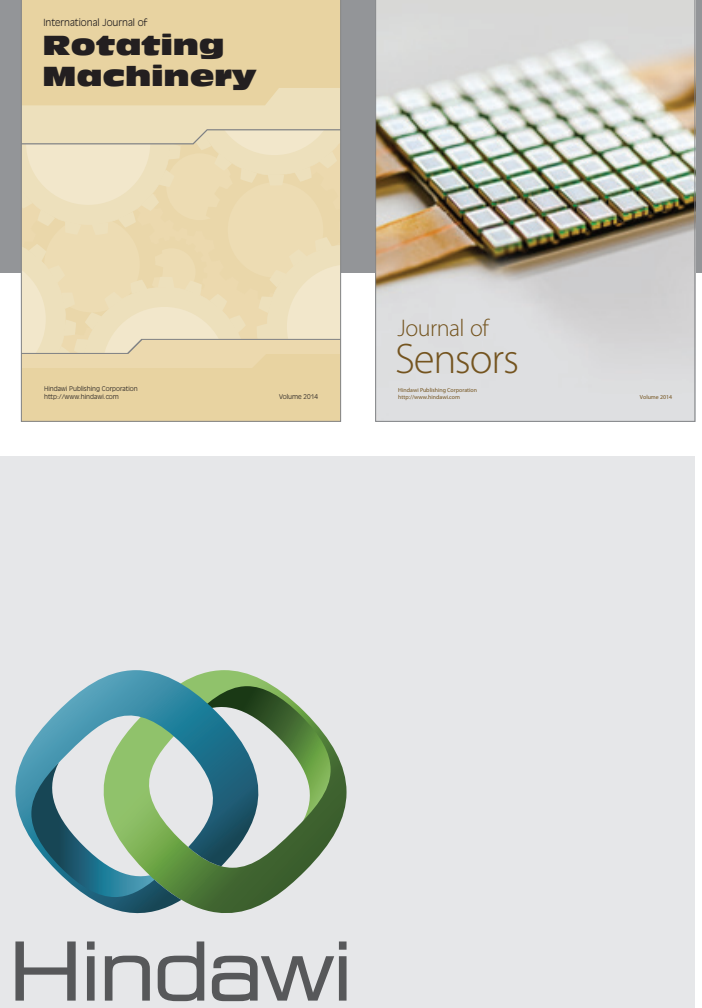

Submit your manuscripts at http://www.hindawi.com
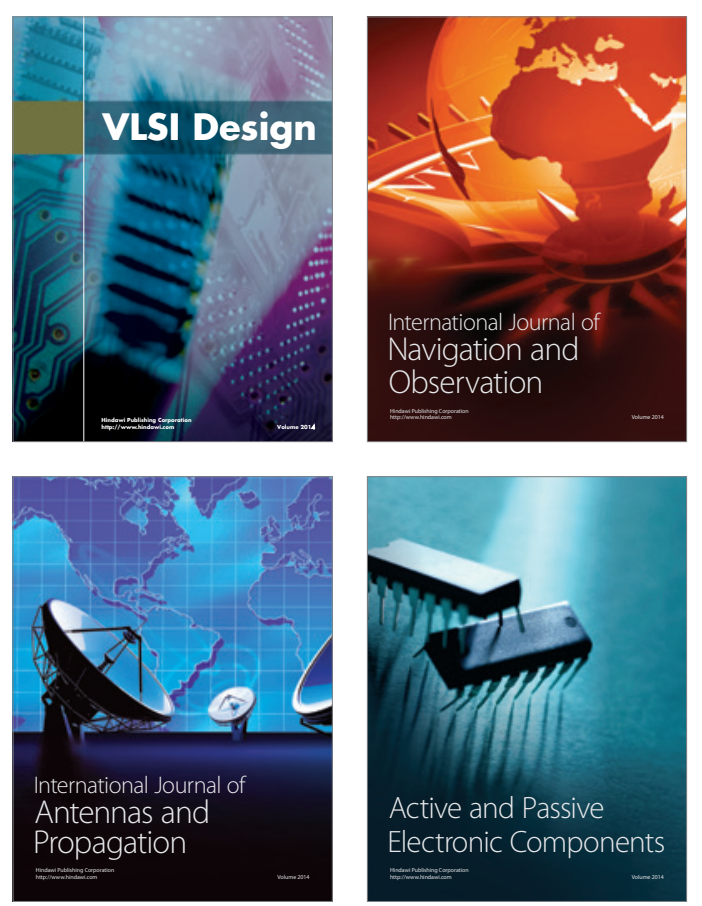
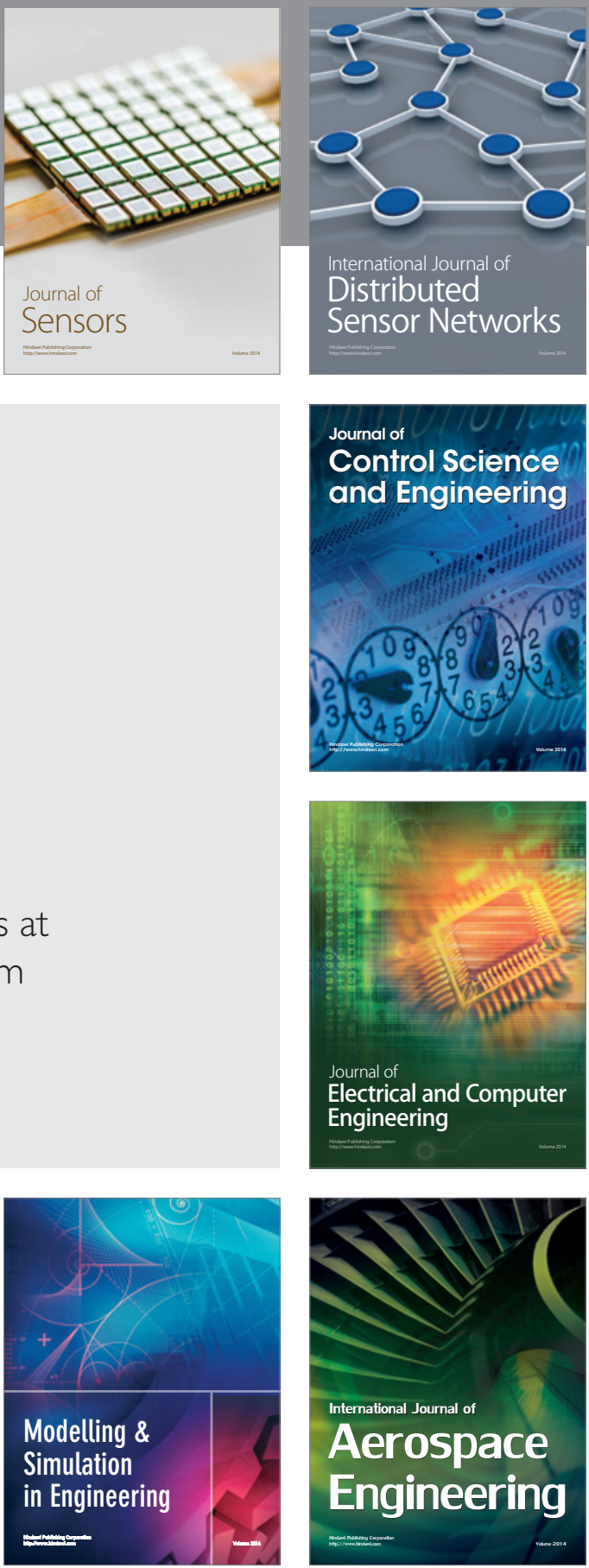

Journal of

Control Science

and Engineering
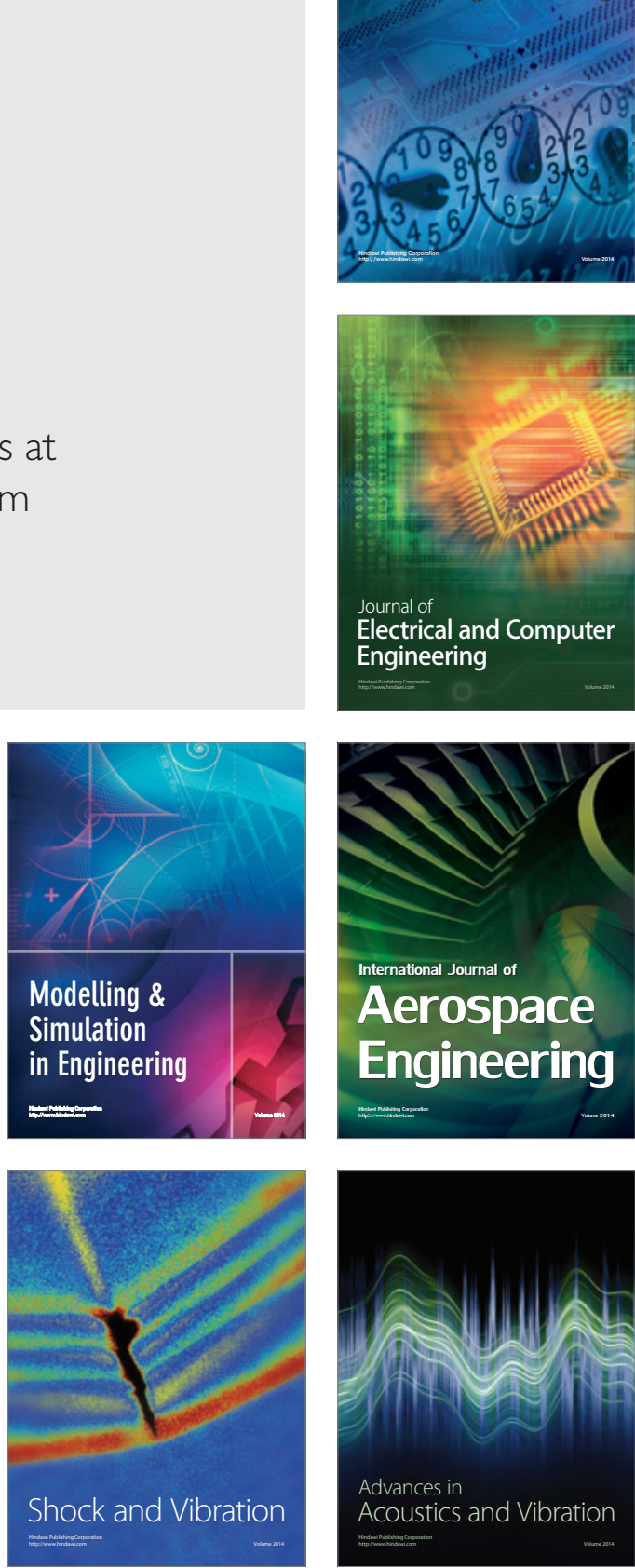